\title{
Disciplinary discourse, representation, and appresentation in the teaching and learning of science
}

\author{
Cedric Linder \\ Division of Physics Education Research, Department of Physics and Astronomy, Uppsala University, Uppsala, \\ Sweden \\ For correspondence: cedric.linder@physics.uu.se
}

\begin{abstract}
This article builds on a semiotic perspective of science learning that is framed in terms of achieving competency in a disciplinary discourse of a science such as physics. The aim of the article is to use this perspective, and the proposal that learning in a science discipline should be seen in terms of achieving fluency in a critical constellation of modes of representation, to explore how the affordance attributes of these representations work together to generate a collective disciplinary affordance. The idea of a collective disciplinary affordance is then used to argue for the importance of appresentation in science education. Recommendations are made for incorporating the discussion into teacher craft-knowledge.
\end{abstract}

Keywords: disciplinary discourse, collective disciplinary affordance, multimodality, representations, appresentation.

\section{Introduction}

In semiotic terms, representations are constructed from collections of signs. In a discipline such as physics these signs are multimodal representations, examples of which are written and spoken language, gestures, symbols, diagrams, sketches, pictures, simulation and imagery, mathematical formalism and so on (see Figure 1). Such representations get their intended signification from the ways that the physics community uses them to produce, interpret, evaluate and share meaning (c.f. Lemke 1990, 1995, 1998). In the context of the teaching and learning of a science such as physics, the meaning-making potentials of representations need to be well understood in order for them to be used in optimal ways. This article explores what this means by drawing on multimodal examples from physics and Airey and Linder's (2009) proposal that, from a disciplinary discourse perspective, learning in a science discipline should be seen in terms of achieving fluency in a critical constellation of modes of representation.

Airey \& Linder (2009, p. 27) modelled disciplinary discourse in terms of "the complex of representations, tools and activities of a discipline". Figure 1 shows the relationship between disciplinary ways of knowing, disciplinary discourse, and different modes of representation that underpins their model. 


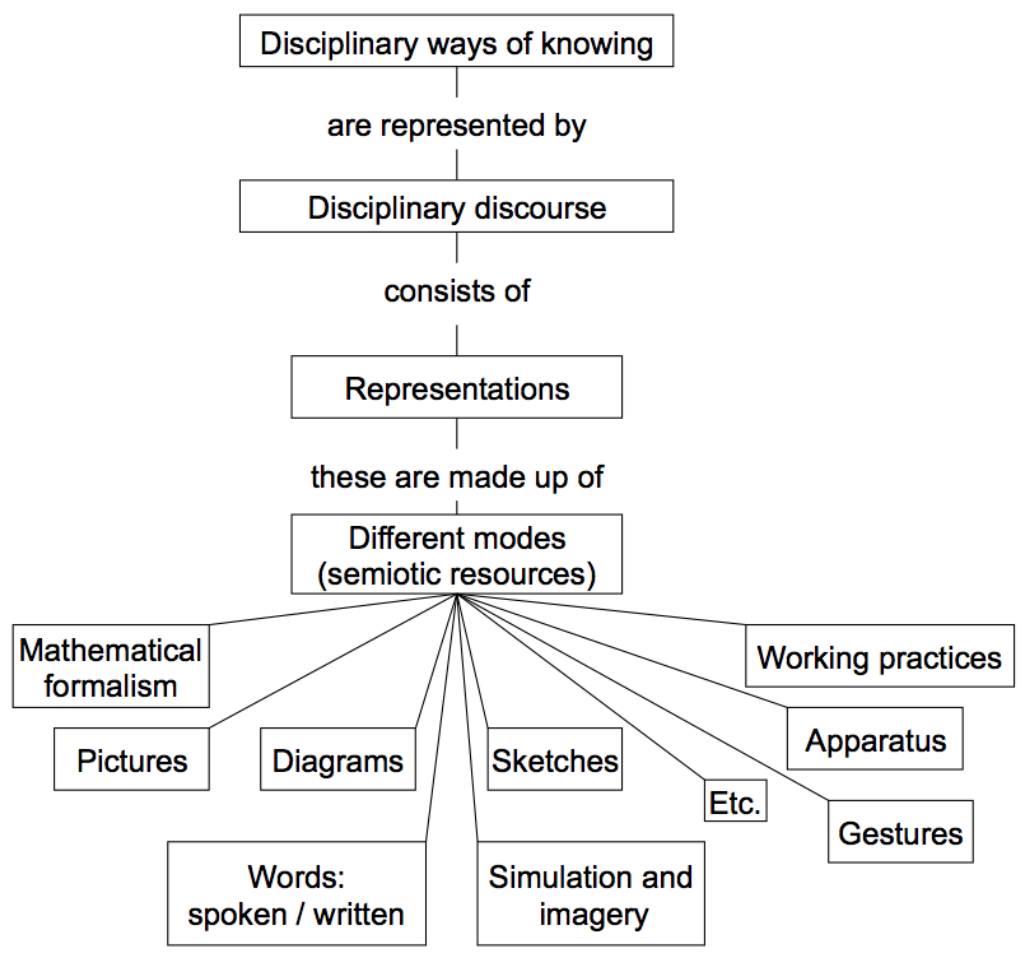

Figure 1. The relationship between disciplinary ways of knowing, disciplinary discourse and different modes of representation (c.f. Airey \& Linder 2009 p. 29).

For the teaching and learning of science a productive way of thinking about the signification of the representations used is in terms of their affordances. This is a term that derives from the work of Gibson (1979) and Norman (1988). Gunther Kress and his colleagues, who are attributed with the development of social semiotics, have incorporated affordance into their theoretical discussions. For example, in relation to the science classroom context Kress et al. (2001) posed the following questions:

What are the affordances of each mode used in the science classroom; what are the potentials and limitations for representing of each mode?"; and, "Are the modes specialized to function in particular ways. Is speech say, best for this, and image best for that? (p. 1)

More recently Fredlund et al. (2012) proposed a refinement of the idea of affordance:

We define the disciplinary affordances of a given representation as the inherent potential of that representation to provide access to disciplinary knowledge. Thus, it is these disciplinary affordances that enable certain representations to become legitimate within a discipline such as physics. Physics learning then, involves coming to appreciate the disciplinary affordances of representations. (p. 658, emphasis added).

If consideration is given to this definition of disciplinary affordance vis-à-vis Airey and Linder's (2009) suggestion that learning in a science discipline should be seen in terms of achieving fluency in a critical constellation of modes of representation, then the following modelling becomes critical: how the affordance attributes of each of the representations in a critical constellation work together to generate a collective disciplinary affordance.

Figure 2, taken from Airey and Linder (2009, p. 33) is used here to illustrate how a constellation of multimodal representations can be seen to present unique and complementary or supplementary affordance attributes. Extrapolating from this, I propose that all of the double-headed arrows in the figure can metaphorically be combined into a collective disciplinary affordance. It is this collective disciplinary affordance that underpins appropriate holistic meaning-making. 


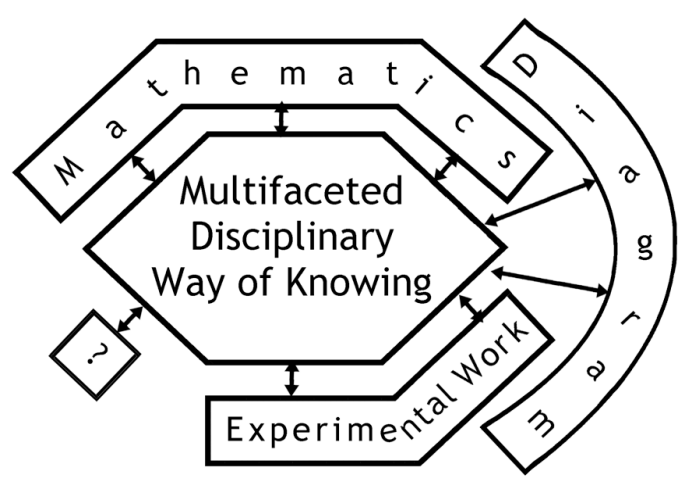

Figure 2. This figure (Airey \& Linder, 2009, p. 33) is used to illustrate how a hypothetical constellation of multimodal representations provides access to unique and complementary or supplementary affordance attributes (represented by double-headed arrows). If these are combined metaphorically then a collective inherent potential emerges; a collective disciplinary affordance.

\section{Affordance attributes}

To illustrate how the affordance attributes of a critical constellation of representations might work together to generate a collective disciplinary affordance, I draw on two examples taken from physics teaching at introductory and intermediate university levels. The first uses an illustration provided by Van Heuvelen (2001, p. 1142) of modes of representation that research has shown to be highly relevant for effective physics problem solving in the given kind of kinematic setting (Van Heuvelen, 1991; Reif \& Heller, 1982, Etkina et al., in press).

(a) Word Description

A car initially moving west at speed $20 \mathrm{~m} / \mathrm{s}$ slows to a stop with an acceleration of magnitude $5.0 \mathrm{~m} / \mathrm{s}^{2}$.

(b) Picture Description

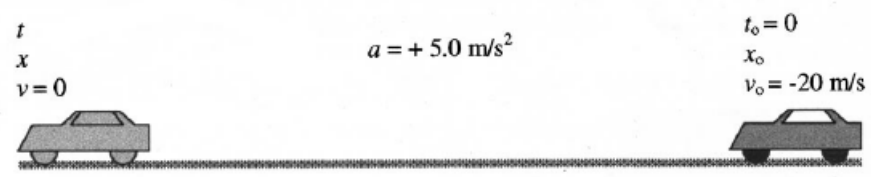

(c) Diagrammatic Description

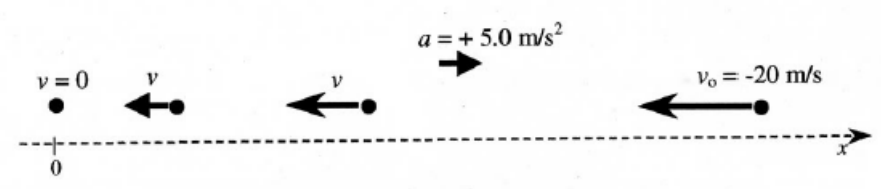

(d) Graphical Description
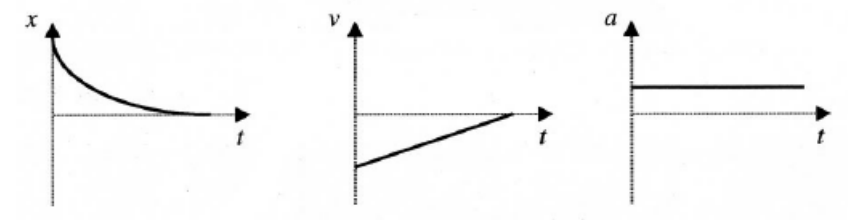

(e) Mathematical Description

$0-(-20 \mathrm{~m} / \mathrm{s})=\left(+5.0 \mathrm{~m} / \mathrm{s}^{2}\right) t$

$x-x_{o}=(-20 \mathrm{~m} / \mathrm{s}) t+0.5\left(+5.0 \mathrm{~m} / \mathrm{s}^{2}\right) t^{2}$

Figure 3. A critical set of modes of representation for a collective disciplinary affordance that can adequately and appropriately guide problem solving for the given kind of kinematic setting (Van Heuvelen, 2001, p. 1142). 
Assuming an equivalency in the written and spoken modes of representation, Figure 3 provides examples of word, picture, diagrammatic and mathematical modes of representation to describe the kinematic process. A typical problem associated with this process would be how far does the car travel? Figure 3 illustrates what different modes of representation should be used to bring to the fore those affordance attributes that are important to solve such a problem in the way that a physicist would reason (Van Heuvelen, 1991; Etkina et al., in press). For example, the pictorial representation does not afford the steady state and changing attributes of the problem that the diagrammatic representation affords. The diagrammatic representation, in turn, does not afford the relationship between these entities and the assigned sign convention (to the left being West and negative) that is afforded by the graphical representation. And, the mathematical representation affords the mathematical formulism of the solution, which is not afforded by any of the other representations. The different affordance attributes are seen by physicists to come together to create a collective disciplinary affordance that facilitates a rich orchestration (Kress \& Van Leeuwen, 2001) of meaning that is braided together in a way that makes the solution of the given type of problem possible.

The second example illustrates how a collective disciplinary affordance can get orchestrated across a complex set of affordance attributes. The example comes from physics and mathematics and is known as the Divergence of a vector field (for this example, a force field, F). The first representation mode would arguably need to be of a word-analogy form in order to afford a general sense of the concept. A good example of such a representation is given by Griffiths (1981):

Imagine you are standing at the edge of a pond. Sprinkle some sawdust or pine needles or something on the surface. If the material spreads out, then you dropped it on a point of positive divergence .... The vector function in this model is the velocity of the surface water .... I am trying to give a "feel" for what the divergence [is] (p 23, emphasis in original).

After (or maybe in conjunction with) this, a mathematical form such as that given below, would be given:

$$
\operatorname{div} \mathbf{F}=\nabla \cdot \mathbf{F}=\frac{\partial F_{x}}{\partial x}+\frac{\partial F_{y}}{\partial y}+\frac{\partial F_{z}}{\partial z}
$$

In order to make sense of the mathematical formalism, further conceptualization that is built on a three-dimensional representational perception would be required. However, because of the complexity involved, it is typical to begin further perception explorations using twodimensional representational imagery (as examples, see Figures $4 \mathrm{a}$ and $4 \mathrm{~b}$ ). Such imagery is usually created through diagrammatic representations and simulation representations such as those provided by Java scripting (for extensive examples of these see Nykamp, on-line Math Insight). 

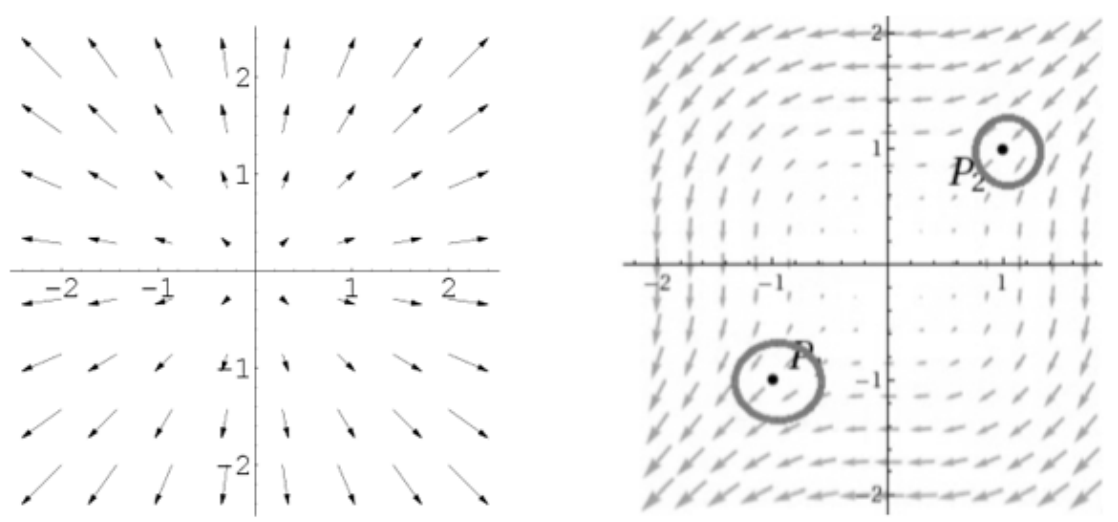

Figure 4a (left). A two-dimensional representational imagery of a vector field $\mathbf{F}$ sourcing (diverging) directly out the paper. Analogically it can be seen as an expansion of fluid flowing with the vector field F. (Nykamp, on-line Math Insight)

Figure $4 \mathrm{~b}$ (right). A diagrammatic representation of how a two-dimensional representation of a vector is changing at two chosen div points, $P_{1}$ and $P_{2}$.

Figure 4a starts the journey of bringing together the disciplinary affordances from the kind of word representation given by Griffiths, the mathematical formalism representation, and the two-dimensional representational imagery. It does this by getting a learner to see Figure $4 \mathrm{a}$ as an expansion of fluid flowing with the vector field F. The complementary affordance that results is now able to facilitate a more holistic understanding of the nature of the divergence at, for example the two given points in the vector field $\mathbf{F}$ as shown in Figure $4 \mathrm{~b}$.

A force field in physics depicts how a non-contact force is modelled to act on a test particle placed in any position in space. The Divergence of such a force field is a way of finding the expansion or contraction or no change condition of the field at a given point in space. In other words, div F gives a way of calculating if the magnitude of the field is increasing in the space just around a given point (div $\mathbf{F}$ would then be positive) or decreasing (div $\mathbf{F}$ would then be negative) or unchanging ( $\operatorname{div} \mathbf{F}$ would then be zero). All of this is afforded from the mathematical representation given earlier, however, it will depend on a certain level of fluency having been attained in the discourse of mathematics. The construction of a, say, small circle, around any point in the field will allow one to visually estimate if the magnitude of the field going into the circle is smaller $(\operatorname{div} \mathbf{F}<0)$, bigger $(\operatorname{dif} \mathbf{F}>0)$ or the same $(\operatorname{div} \mathbf{F}=$ 0 ). See Figure $4 \mathrm{~b}$ for a two-dimensional representational imagery that helps facilitate the constitution of the collective disciplinary affordance. The figure supplies the representational imagery needed to start to constitute a collective affordance with the word and mathematical formalism representations as follows: Create two spatial areas around the points of interest in the imagery of the vector field. Then see if the magnitude of the field entering the spatial area is the same, greater or less when exiting the spatial area. An examination of the small spatial area around the points (marked as small circles) in Figure $4 \mathrm{~b}$ illustrate how $\operatorname{div} \mathbf{F}$ at $\mathrm{P}_{1}$ gets to be seen as being greater than zero (i.e. diverging and positive) and $\operatorname{div} \mathbf{F}$ at $\mathrm{P}_{2}$ gets to be seen as being less than zero (i.e. converging and negative).

These illustrations have been used to make a case that a set of carefully selected multimodal representations, each with their own (unique, supplementary or complementary) affordances, is needed in order to generate a collective disciplinary affordance. However, a person who has attained disciplinary fluency in physics would conceivably not need to draw on all of these representations for their meaning-making and problem solving. The process of becoming fluent in the disciplinary discourse would have required them to learn to see not only what a particular mode of representation affords, but also what affordance lies behind the constitution of the collective disciplinary affordance. This seeing what is co-present, or lying behind a representation, is characterized as appresentation. 


\section{Appresentation}

The notion of appresentation is illustrated by Marton and Booth (1997) using a tabletop as an example:

.... in addition to what is "presented" to us - that is what we see, hear, smell - we experience other things as well. If we look at a table top from above, for instance, we hardly experience it as a two-dimensional surface floating in the air, in spite of the fact that what we see is, strictly speaking, a two-dimensional surface separated in some mysterious way from the ground. But in looking down on a tabletop we experience the legs that support it as well, because the experience is not of a two-dimensional surface, but of a table... That which is not seen, is not even visible, is appresented ...

We wish to apply the concept of appresentation to experiences of abstract entities as well as concrete ones. If we think of the gravitational constant, $g$, for instance, then the highly abstract formulation made by Newton of how bodies affect one another at a distance is appresented, given that we have acquired sufficient education in and experience of classical physics (pp. 99100, emphasis added).

To illustrate the importance of having access to appresentation in the quest for attaining fluency in a disciplinary discourse, consider some of the basic aspects that are required for an appropriate understanding of Kirchoff's Voltage Law. These range from the physics of the conservation of energy in a circuit (such as, having no changing magnetic field associated with the circuit) to being able to apply sign conventions across emf (electromotive force) sources and resistor and capacitor components that are not simply algorithmic. An example of what needs to be appresented for all the representations in Figure 5 is that, as a consequence of the electric fields being conservative, the total work performed in moving a charge around a closed path will be zero. In the mathematical formalism representation of the circuit, unless the applicable potential differences for any inductors are first calculated using an electric field line integral, the exclusion of inductors from a circuit needs to be appresented in order to decide if Kirchoff's Voltage Law can be used for the circuit.

A metaphorical step behind the kind of appresentation attributes just discussed is another whole realm of possible appresent physics knowledge and applications that underpin circuit analysis, for example the concepts of ideal wires, junctions, power sources and so on.

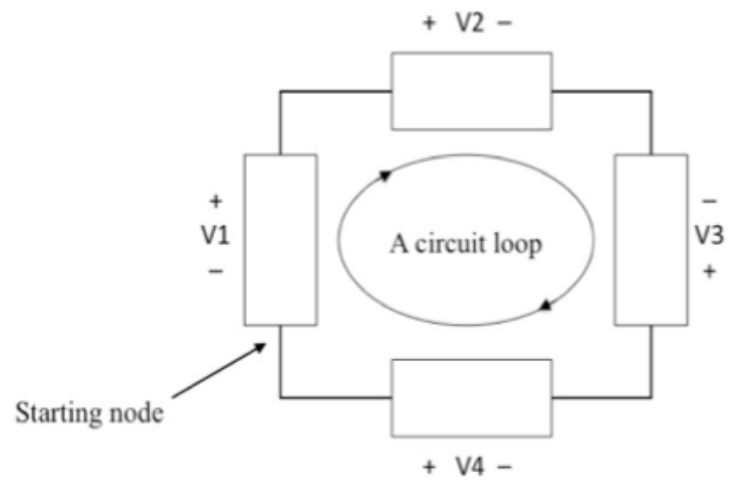

$$
\begin{aligned}
& \text { The directed algebraic sum } \\
& \text { of the electrical potential } \\
& \text { differences (voltage } \\
& \text { differences) across circuit } \\
& \text { components in any piece of } \\
& \text { closed loop in a circuit will } \\
& \text { be zero } \\
& V_{1}-V_{2}+V_{3}+V_{4}=0 \\
& V_{2}=V_{1}+V_{3}+V_{4} \\
& \sum_{n=1}^{N} V_{n}=0
\end{aligned}
$$

Figure 5. A constellation of three representations that have a collective disciplinary affordance for Kirchoff's Voltage Law.

\section{Summary and recommendations for teachers}

I began this article by suggesting that to optimize the teaching and learning of science the meaning-making potential of representations needs to be well understood vis-à-vis a 
disciplinary discourse perspective, which calls for science learning to be viewed in terms of attaining fluency in a critical constellation of modes of representation. Using the idea of disciplinary affordance, I proposed the idea of a collective disciplinary affordance for critical constellations of representation. To illustrate this I used examples from physics to show how individual representations can provide access to both unique and complementary or supplementary affordance attributes, which together would constitute the collective disciplinary affordance of the critical constellation of representations.

A person who has achieved fluency in the disciplinary discourse of physics is able to see the affordance attributes that are appresented in the constitution of a collective disciplinary affordance. However, what is critical for the teaching and learning of physics is that a physics teacher is able to make this visible to learners. Teachers who use a limited multimodality of representations in their teaching will be unable to achieve this; unable to afford an appropriate holistic learning experience.

Teacher craft-knowledge needs to include an appreciation of what modes are necessary to open up possible access to all the different parts of a disciplinary way of knowing needed for an intended learning outcome. This involves knowing the disciplinary affordance of the various modes used and how their collective disciplinary affordance meets the intended learning outcome. However, drawing on a particular set of modes of representation in science teaching will not be sufficient in itself. The possibility for learners to become discursively fluent in these modes has another critical feature: the ability to be able to see what is appresented, that is, what lies behind the representations and the constellations of them that afforded the intended learning outcome.

\section{Acknowledgements}

This article is derived from my keynote presentation at the inaugural Frontiers in Science Education Research Conference, Eastern Mediterranean University, Famagusta, North Cyprus, 22-24 March, 2009.

I thank Anne Linder for her insightful comments on drafts of this article, Tobias Fredlund for his help with the Figures, and Alan Van Heuvelen for his permission to use his material in Figure 3.

Funding from the Swedish Research Council is gratefully acknowledged.

\section{References}

Airey, J., and Linder, C. (2009). A Disciplinary Discourse Perspective on University Science Learning: Achieving Fluency in a Critical Constellation of Modes. Journal of Research in Science Teaching, 46(1), 27-49.

Etkina, E., Gentile, M. and Van Heuvelen, A. (In press). Active learning guide for college physics. Pearson.

Fredlund, T., Airey, J., and Linder, C. (2012). Exploring the role of physics representations: an illustrative example from students sharing knowledge about refraction. European Journal of Physics, 33(3), 657-666

Gibson, J. J. (1979). The theory of affordances. In The Ecological Approach to Visual Perception (pp. 127-143). Boston: Houghton Miffin.

Griffiths, D.J. (1981). Introduction to Electrodynamics (First Edition). New Jersey: Prentice Hall.

Kress, G., Jewitt, C., Ogborn, J., and Tsatsarelis, C. (2001). Multimodal teaching and learning: The rhetorics of the science classroom. London: Continuum.

Kress, G., and van Leeuwen, T. (2001). Multimodal discourse: The modes and media of contemporary communication. London: Edward Arnold.

Lemke, J. L. (1990). Talking science: Language, learning and values. Norwood, NJ: Ablex.

Lemke, J. L. (1995). Intertextuality and text semantics. In Fries, P. H. and Gregory, M. (Eds.), Discourse in society: Systemic functional perspectives. Meaning and choice in language (pp. 85-114). Norwood, NJ: Ablex.

Lemke, J. L. (1998). Teaching all the languages of science: Words, symbols, images, and actions. http:/ / academic.brooklyn.cuny.edu/education/jlemke/papers/barcelon.htm (accessed September 2005)

Marton, F. and Booth, S. (1997). Learning and Awareness. Mahwah, N. J.: Lawrence Erlbaum.

Nykamp, D. Q. (on-line) Math Insight. http://mathinsight.org

Norman, D. A., (1988). The Psychology of Everyday Things. Basic Books, New York.

Reif, F. \& Heller, J.I. (1982). Knowledge structure and problem solving in physics. Educational Psychologist, 17(2), 102127.

Van Heuvelen, A. (1991). Overview, case study physics, American Journal of Physics. 59, 898-907.

Van Heuvelen, A. (2001). Millikan Lecture 1999: The Workplace, Student Minds, and Physics Learning Systems Am. J. Phys. 69, 1139-1146.

Van Heuvelen, A. and Etkina, E. (2006). Active Learning Guide. USA: Addison-Wesley. 